\title{
Article
}

Arq Neuropsiquiatr 2011;69(5):770-774

\section{Self-esteem, social support perception and seizure controllability perception in adolescents with epilepsy}

\author{
Nathália F. Siqueira, Marilisa Mantovani Guerreiro, \\ Elisabete Abib Pedroso de Souza
}

\begin{abstract}
Objective: Compare the self-esteem of adolescents with epilepsy and adolescents without epilepsy and relate it to social support and seizure controllability perception. Method: The study sample consisted: case participants (34 subjects) attending the pediatric epilepsy clinic of University Hospital and control participants (30 subjects) from public schools in Campinas-SP. The instruments utilized were: identification card with demographic and epilepsy data, a semi-structured interview on aspects of the disease, and a SelfEsteem Multidimensional Scale. Results: There was no significant difference between the two groups but majority of adolescents with epilepsy presented higher self esteem rate, have knowledge about epilepsy, presented high levels of social support and seizure controllability perception. There was no significant relationship between social support and seizure controllability perception with self-esteem. Conclusion: Knowledge about epilepsy, social support such good controllability seizure perception seem are important contingencies for a better evaluation of self esteem in adolescents with epilepsy.

Key words: self-esteem, social support, controllability, adolescents, epilepsy.
\end{abstract}

Autoestima, percepção de suporte social e percepção de controlabilidade de crises em adolescentes com epilepsia

\section{RESUMO}

Objetivo: Comparar a autoestima de adolescentes com epilepsia e adolescentes sem epilepsia e relacioná-la com percepção de suporte social e controlabilidade de crises. Método: A amostra do estudo consiste: grupo caso (34 sujeitos) atendidos no ambulatório de epilepsia infantil do Hospital Universitário e grupo controle (30 indivíduos) de escolas públicas de Campinas-SP. Os instrumentos utilizados foram: cartão de identificação com dados demográficos e de epilepsia, entrevista semiestruturada sobre os aspectos da doença e Escala Multidimensional de autoestima. Resultados: Não houve diferença significativa entre os dois grupos, mas a maioria dos adolescentes com epilepsia apresentou maior pontuação de autoestima, conhecimento sobre epilepsia, altos níveis de suporte social e percepção de controlabilidade das crises. Não houve relação significativa entre suporte social e percepção de controlabilidade das crises com a autoestima. Conclusão: Conhecimento sobre a epilepsia, percepção de apoio social assim como boa controlabilidade de crises parecem ser contingências importantes para uma melhor avaliação da autoestima em adolescentes com epilepsia.

Palavras-Chave: autoestima, suporte social, controlabilidade, adolescentes, epilepsia.

Correspondence

Nathália F. Siqueira

Dep. Neurologia / FCM / UNICAMP

Caixa Postal 6111

13083-970 Campinas SP - Brasil

E-mail:nfsiqueira@gmail.com

Received 11 May 2011

Received in final form 16 May 2011

Accepted 23 May 2011
Adolescence is a life stage characterized by intense emotional and physical transformation ${ }^{1}$. These young people are overwhelmed by intense feelings, while going through significant changes and assuming new behaviors ${ }^{1}$.

In individuals with some degree of any disease, adolescence may be particularly 
troublesome. Adolescents with epilepsy may become depressed by their medical and psychological problems and this may lead to a breakdown ${ }^{2}$. Epilepsy during adolescence may significantly affect social development and maturation as a result of stigmatization, and may also impair independence, social function, relationships, self esteem, mood and cognition ${ }^{3}$. Literature data showed that children and adolescents with epilepsy have a low self-esteem ${ }^{4,5}$.

A positive self esteem is a human need, essential to healthy adaptation, and significantly associated with personal satisfaction and ideal functionality ${ }^{6}$. Self-esteem expresses an attitude of approval or disapproval, and indicates the extent to which the individual believes himself to be capable, significant, successful, and worthy. In short, self-esteem is a personal judgment of worthiness that is expressed in the attitudes the individual holds toward himself ${ }^{6}$. The feelings about having epilepsy, as well as the perception of others' reaction, may influence self esteem and the value patients give themselves.

Moreover, patients with chronic disease build a cognitive representation of the illness that has to do with the way it involves knowledge of what he has (label) and as he sees himself (self-esteem) ${ }^{7-9}$. Identifying the representation and coping strategies are important approaches to understand how the adolescents interpret their experience with chronic disease. Two important contingencies in this context are the social support perception (related to social) and seizure controllability perception (related to disease).

The social support is a pillar that supports the individual and that can give meaning to their existence. Coopersmith ${ }^{6}$ highlights the positive effect of parental acceptance on self-esteem in particular and psychosocial development in general. In epilepsy, social contacts and familiar relationships are an important source of social support and may have great impact on the individual ability to cope with the disease ${ }^{10-12}$.

People with epilepsy often believe that they have little control over his condition and his life. These beliefs and feelings are generated by the unpredictability of the seizures, failure to control their own bodies, medication dependence and dependence on others ${ }^{13}$.

The personal perception that seizures are under control or not is related to the way in which the patient behaves and his self-assessment of the quality of life. The patient may not have seizures anymore, but if he still worries about having them, then his quality of life is affected the same way. When the subject perceives that he has no control over their responses, his sense of self-determination becomes injured and flawed ${ }^{9}$.

Moreover, other factors directly or indirectly may influence the emotional development in chronically ill and is linked to knowledge related to their condition. Knowledge regarding epilepsy may be important in reducing the impact of seizure, potentially harmful self-management practices, and the emotional impact of both seizures and treatment ${ }^{14,15}$. Hirfanoglu et al. ${ }^{15}$ study suggests that the individuals with epilepsy who know less about their disease have a worse self-concept than those who know more, and it is associated with perceived lack of social support.

In recent decades there is a greater interest in the study of variables that control the impact of epilepsy, variables that go beyond the seizures, noted the importance of psychosocial conditions and their influence in determining the well-being of individuals in a chronic medical condition. Working in this direction, we developed this study in order to examine the self-esteem of adolescents with epilepsy and compare it with the self esteem of adolescents without epilepsy and relate it to seizure controllability perception and social support perception.

The aim of this study was to compare the self-esteem of adolescents with epilepsy and adolescents without epilepsy and relate it to seizure controllability perception and social support perception.

\section{METHOD}

\section{Participants}

The study sample consisted of 64 adolescents assessed in the year 2009. Case participants (34 subjects with epilepsy) attending the pediatric epilepsy clinic of our University Hospital. Control participants (30 subjects without epilepsy) were selected from public schools in Campinas-SP. All participants were students and attended regular schools at the appropriate level for chronological age. The inclusion criteria were: age between 11 to 18 years ${ }^{16}$, ability to answer the questions by himself/ herself, medical diagnosis of epilepsy for more than 2 years (criteria established in service for epilepsy diagnosis) for the group with epilepsy and no diagnosis of epilepsy for the group without epilepsy. The exclusion criteria for both groups were: if they had had brain surgery, used a concomitant medication with central nervous system effects, or had another progressive neurological or psychiatric illness.

Mean years of case group was 13,94 $(\mathrm{SD}=2.25)$ and of control group was 12.73 ( $\mathrm{SD}=1.72)$. The most adolescents of case group was female (55.88\%), students (100\%), attending elementary school (67.64\%). The most adolescents of control group was female (66.66\%), students (100\%), attending elementary school (83.33\%). Most adolescents of case group had focal plus generalized seizures (50\%), frequent seizures (73.52\%), onset seizure between five to nine years $(38.23 \%)$ and were on monotherapy (76.47\%). 
The patients, who voluntarily participated of this study, signed an informed consent. This study was approved by the Committee of Ethics on Medicine of the State University of Campinas (UNICAMP).

\section{Measures}

[1] Identification card with demographic data (age, sex, education level, and job) and epilepsy data (age of onset, seizure frequency, type of seizure and drug treatment). Regarding frequency of seizure were considered two groups: frequent seizure (seizures that occurs in a period of seven to thirty days) and no frequent (patients without seizures or seizures in a period of six months to one year). Type of seizure was classified according to the International League Against Epilepsy classification of epileptic seizures ${ }^{17}$ - focal seizures, generalized seizures, focal + generalized seizures. Drug treatment was classified in monotherapy (one type of medication) and polytherapy (two or more medication).

[2] A semi-structured interview intended only for adolescents with epilepsy containing three questions on aspects of the disease: - Do you know what do you have? With whom did you learn? - Do you consider that your seizures are controlled? - Do you perceive social support?

An analysis was made of the reports and responses were categorized. In respect to seizure controllability perception and social support perception both were categorized in two types (control or not, and support or not).

[3] Self-Esteem Multidimensional Scale. This inventory is a Brazilian version of the Self-Esteem Inventory $^{18}$, corrected for validity and reliability by Gobitta ${ }^{19}$. This scale consists of 56 statements about situations that may or may not happen with the person and personal feelings that may or may not exist. Five dimensions are evaluated (self, social group, family, school and responsability), but in this study only the general self-esteem - according to the criteria established by Coopersmith - was considerated. The cutoff criterion was 224 points: a score below this value considers that the subject has low self-esteem; and above or equal the cutoff value suggests that the subject has high self-esteem. This instrument does not appear commercially, but can be accessed directly with the author.

\section{Procedure}

The selection of subjects of case group obeyed the demand of our neurology outpatient clinic according to the criteria for inclusion and exclusion, acceptance of the subject and responsibility to take the research. Information on disease variables were collected from a data collection by reading patient's records. On the day of outpatient consultation, the researcher invited the subject and his companion (the one with legal responsibility over the subject) to participate in the research. The selection of subjects of control group was made randomly in schools obeying the homogeneity in gender and age according to the criteria of inclusion and exclusion. Two public schools were chosen by lottery. After the headmaster's authorization, the students were taught about the research and those who had an interest in participating took the written informed consent home to get their parents' signed authorization.

All the adolescents of case group were interviewed individually by response research at the outpatient clinic of Psychology Applied to Neurology at the University Hospital. All the adolescents of control group were interviewed at the individual class of their school.

The interviews of adolescents of case group were performed on two nonconsecutive days. On the first day, the objective was to create a positive bond between the professional and patient. On the second day, one week later the objective was to apply the tools of research. The interviews of adolescents of control group were performed on one day. The objective was to apply the self esteem multidimensional scale.

It was expected that adolescents of case group (with epilepsy) have impaired self-esteem compared to adolescents of control group (without epilepsy).

\section{Statistics analysis}

To describe the sample profile according to the study variables, data were categorical variables with values of percentage (\%) and descriptive statistics (with measurements of position and dispersion - mean, standard deviation, minimum, maximum, median and quartiles) for continuous variables (scores of scales).

To compare categorical variables between the groups we used the Fisher Exact test (to expected values lower than 5). To compare numerical variables between two groups we used the Mann-Whitney test. The level of significance for statistical test was $5 \%(\mathrm{p}<0.05)$

\section{RESULTS}

Date of self-esteem from both groups are listed in Table 1.

Twenty nine patients of case group presented high self esteem (85.29\%) and five subjects with epilepsy presented low self esteem (14.70\%).

Seventeen subjects of control group presented high self esteem (56.66\%) and thirteen subjects without epilepsy with low self esteem (43.33\%).

There was no significant difference between the two groups. The aspects of epilepsy were identified at the semi-structured interview.

Regarding the knowledge about epilepsy, most adolescents in our study knew that they had epilepsy 
Table 1. Results of self-esteem in case group and control group.

\begin{tabular}{lcccccc}
\hline Dimensions & Mean & SD & Min & Median & Max & Value p $^{*}$ \\
\hline Case group & 229.17 & 29.52 & 161.00 & 223.50 & 272.00 & 0.406 \\
Control group & 222.80 & 32.48 & 109.00 & 231.50 & 264.00 & \\
\hline
\end{tabular}

*Value-p referring to the test of Mann-Whitney to compare variables between groups (with epilepsy $\times$ without epilepsy). SD: standard deviation; Min: minimum; Max: maximum.

Table 2 . Self esteem $\times$ social support perception $\times$ seizure controllability perception.

\begin{tabular}{|c|c|c|c|c|c|c|}
\hline \multirow{2}{*}{$\frac{\text { Self-esteem }}{\text { Frequency }}$} & \multicolumn{2}{|c|}{ Social support } & \multirow[t]{2}{*}{$p^{*}$} & \multicolumn{2}{|c|}{ Seizure control } & \multirow[t]{2}{*}{$\mathrm{p}^{* *}$} \\
\hline & No & Yes & & No & Yes & \\
\hline Self-esteem low & $3(60 \%)$ & $8(32 \%)$ & & $2(40 \%)$ & $9(36 \%)$ & \\
\hline Self - esteem high & $2(40 \%)$ & $17(68 \%)$ & & $3(60 \%)$ & $16(64 \%)$ & \\
\hline Total & 5 & 25 & 0.327 & 5 & 25 & 1.000 \\
\hline
\end{tabular}

*Fisher Exact Test: $p=0.327$; **Fisher Exact Test: $p=1.000$.

$(61.76 \%)$ and learned about epilepsy through doctors (67.64\%).

Regarding the social support perception, most adolescents (83.33\%) reported support. Most of them reported receiving social support from family and friends (41.17\%), 35.29\% reported receiving only from family, $14.17 \%$ reported not receiving support at all and $8.82 \%$ reported receiving support only from friends.

Regarding their seizure controllability perception, 25 patients (83.33\%) felt they had good control.

Comparisons between the variables self-esteem and seizure controllability perception and self-esteem and social support perception are listed in Table 2.

The results indicate that there was no significant relationship between variables.

\section{DISCUSSION}

Our study showed no significant difference between groups although case group presented higher self esteem rate compared with control group.

Lee et al. ${ }^{20}$ found similar results to our study in which scores of self concept in adolescent with epilepsy were compared to standard mean and there were no significant differences.

These latter findings are particularly surprising, because epilepsy was reported to correlate with a poor prevalence of self esteem ${ }^{2-5}$. This discrepancy may be explained by several factors. A sample from our customer references and inclusion/exclusion criteria limited the number of subjects. Moreover, some investigated aspects show that our adolescents have characteristics that may explain our results, such as good knowledge of epilepsy, social support perception and seizure controllability perception as discussed below.

Were used interviews were aimed at identifying the data related to knowledge about epilepsy, social support perception and seizure controllability perception. This data was analyzed after they had been categorized.

The majority of adolescents in our study knew that they have epilepsy. Most of them learned about epilepsy through doctors, and this increases the responsibility of health professionals in delivering adequate information. However, a lack of knowledge about epilepsy in the general population is still observed ${ }^{21,22}$.

Our sample showed that the knowlegde about epilepsy may influence the way adolescents relate to the disease and may provide greater success in adapting and accepting the limits imposed by epilepsy. Increased knowledge about epilepsy may promote a valuable way to adaptation, acceptance and increased self-esteem and quality of life.

Other factor that deserves to be mentioned in our study was the presence of high prevalence social support. The adolescents who found it easy to talk to their parents and friends about their problems had a better chance of facing the illness in a more adequate way. A study by Thorton et al. ${ }^{23}$ showed that family with children with epilepsy obtained significantly better results in the involvement subscale (measuring aspects such as empathy, degree of fulfillment of emotional needs, care and support interactions among family members) than the standard average. According to the authors, because their children have epilepsy, parents can become more involved and care more, reflecting a positive impact in self esteem of children with epilepsy.

Social support is thought to buffer the negative impact of stressful events, ongoing life strains, and chronic health conditions. Most importantly, social support was a mediator between disease severity and mastery, defined as patients' general belief that they can control the course of life despite their epilepsy. As social support increases, the sense of mastery increases, and the person's 
ability to cope with the limitations of their disease improves, influencing directly health ${ }^{13,24}$.

Social support by family members, close friends and significant others seems to facilitate a better health care, foster a sense of meaning of illness, promote appropriate behaviors, reduce risk factors contributing to the individual learns to deal with possible limitations. Social support seems therefore act as a protective factor for self-esteem of adolescents with epilepsy.

In our study, although most adolescents had frequent seizures perceived their seizures as being controlled, which favored a positive self-evaluation of the disease and a better personal recovery.

A perception of good seizure controllability seems to facilitate social contacts and a normal life. Souza and Salgado ${ }^{9}$ draws attention to the perceived controllability like important factor in control of the disease, even if, from the medical perspective, the disease is not considered controlled. Patient may have frequent seizures, but these decreased in the current period as he may deem it under control. According the authors, the perception of seizure control seems to be an important factor to mitigate the impact of experiences potentially stressful. Studies of Gertrudis et al. ${ }^{25}$ also point out that the way the individual experiences his seizures has no direct relationship with the severity of seizures, but with adaptation strategies that individuals adopt and the ways they define their clinical reality, social and personal.

The use of more positive coping strategies can change the meaning of the seizures, making the situation more acceptable.

Our results seem to indicate that knowledge about epilepsy, social support factors such good controllability seizure perception promote a better evaluation of self esteem in adolescents with epilepsy.

Our study showed, independently, high rates of self-esteem, social support perception and seizure controllability perception in adolescents with epilepsy. Although the statistic analysis showed no relationship between these factors, these results could be explained in view to the homogeneity between these variables in a small sample.

Understanding about the various contingencies of self esteem is very important because help to reduce the power of prejudice and to reduce the impact of stressor stimuli (disease), increase adherence to therapy and improve quality of life in general and diminished behavioral problems and competence problems ${ }^{12,13,23}$.

Further studies are needed to allow a better understanding of the meaning, representation and personal perception of the disease in adolescents, through paradigms with a greater number of subjects and comparing groups of adolescents from different social groups and family attitudes.

\section{REFERENCES}

1. Polanczyk GV, Denardin D, Laufer T, Pianca T, Rohde LA. O transtorno de déficit de atenção/hiperatividade na adolescência. Adolesc Latinoam 2002;3:1-23.

2. Sbarra DA, Rimm-Kaufman SE, Pianta RC. The behavioral and emotional correlates of epilepsy in adolescence: a 7-year follow-up study. Epilepsy Behav 2002;3:358-367.

3. Eklund PG, Sivberg B. Adolescents lived experience of epilepsy. J Neurosci Nurs 2003;35:40-49.

4. Austin JK, Huster GA, Dunn D, Risinger MW. Adolescents with active or inactive epilepsy or asthma: a comparison of quality of life. Epilepsia 1996; 37:1228-1238.

5. Mcewan MJ, Espie CA, Metcalfe J. A systematic review of the contribution of qualitative research to the study of quality of life in children and adolescents with epilepsy. Seizure 2004;13: 3-14.

6. Coopersmith S. The antecedents of self-esteem. San Francisco: Freeman, 1967.

7. Leventhal H, Nerenz DR. The assessment of illness cognition. In: Karoly P (Ed). Measurement strategies in health psychology. New York: Wiley, 1985

8. Leventhal $H$, Diefenbach $M$. The active side of illness cognition. In: Skelton JA, Croyle RT (Eds). Mental representations in health and illness. New York: Springer-Verlag, 1991.

9. Souza EAP, Salgado PCB. A psychosocial view of anxiety and depression in epilepsy. Epilepsy Behav 2006; 8: 232-238.

10. Aydin K, Yildiz H. Teachers' perceptions in central Turkey concerning epilepsy and asthma and the short-term effect of a brief education on the perception of epilepsy. Epilepsy Behav 2007;10:286-290.

11. Charyton C, Elliot JO, Lu B, Moore L. The impact of social support on health related quality of life in persons with epilepsy. Epilepsy Behav 2009; 16:640-645

12. Mccgah J, Fisk JE, Baker GA. Epilepsy, psychosocial and cognitive functioning. Epilepsy Res 2009;86:1-14

13. Amir M, Roziner I, Knoll A, Neufeld MY. Self-efficacy and social support as mediators in the relation between disease severity and quality of life in patients with epilepsy. Epilepsia 1999;40:216-224.

14. Bozkaya IO, Arhan E, Serdaroglu A, Soysal AS, Ozkan S, Gucuyener K. Knowledge of, perception of, and attitudes toward epilepsy of schoolchildren in Ankara and the effect of an educational program. Epilepsy Behav 2010;17:56-63.

15. Hirfanoglu T, Serdaroglu A, Cansu A, Soysal S, Derle E, Gucuyener K. Do knowledge of, perception of, and attitudes toward epilepsy affect the quality of life of Turkish children with epilepsy and their parents? Epilepsy Behav 2009;14:71-77.

16. Organización Mundial de la Salud. Programación para la salud y el desarrollo de los adolescentes: informe de un grupo de estúdio. Suiza: Saillon, 1995.

17. Commission on Classification and Terminology of the International League Against Epilepsy. Proposal for revised clinical and electroencephalographic classification of epileptic seizures. Epilepsia 1981;22:489-501.

18. Coopersmith S. Coopersmith Self-Esteem Inventory. Palo Alto (CA): Consulting Psychologists Press, 1989.

19. Gobbita M. Escala Multidimensional de Autoestima (EMAE): construção e validação com crianças e adolescentes brasileiros. (Tese: Doutorado). Pontifícia Universidade Católica de Campinas, Campinas 2003.

20. Lee A, Hamiwka LD, Sherman SEM, Wirrell EC. Self-concept in adolescents with epilepsy: biological and social correlates. Pediatric Neurology 2008;38:335-339.

21. Austin JK, Shafer PO, Deering JB. Epilepsy familiarity, knowledge, and perceptions of stigma: report from a survey of adolescents in the general population. Epilepsy Behav 2002;3:368-375.

22. Njamnshi AK, Angwafor SA, Tabah EN, Jallon P, Muna WF. General public knowledge, attitudes and practices with respect to epilepsy, in the Batibo Health District, Cameroon. Epilepsy Behav 2009;14:83-88.

23. Thornton N, Hamiwka L, Sherman E, Tse E, Blackman M, Wirrell E. Family function in cognitively normal children with epilepsy: impact on competence and problem behaviors. Epilepsy Behav 2008;12:90-95.

24. Stansfeld SA. Social support and social cohesion. In: Marmot MG, Wilkinson RG (Eds). Social determinants of health. New York: Oxford Univ. Press, 1999:148-171.

25. Gertrudis IJM, Kempen PRD, Ormel J, Brilman I, Relyveld J. Adaptative responses among Dutch elderly: the impact of eight chronic medical conditions on HRQOL. Am J Public Health 1997;87:251-270. 